\title{
Unexpected Variations in Sites of Lithiation of $\mathrm{N}$-(2-Methoxy- benzyl)pivalamide
}

\author{
Keith Smith,* Gamal A. El-Hiti and Amany S. Hegazy \\ School of Chemistry, Cardiff University, Main Building, Park Place, Cardiff CF10 \\ 3AT, U.K. \\ smithk13@cardiff.ac.uk
}

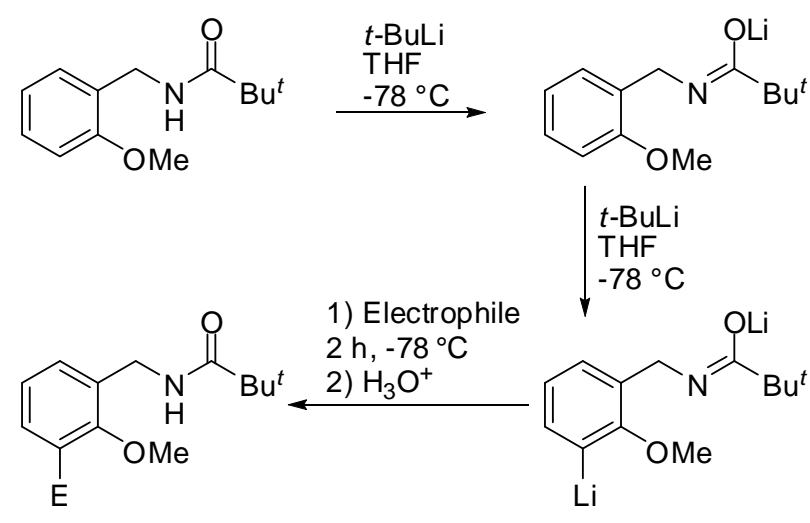

$73-86 \%$

Electrophile $=\mathrm{CO}_{2}, 4-\mathrm{MeOC}_{6} \mathrm{H}_{4} \mathrm{CHO}, \mathrm{PhCHO}, \mathrm{Ph}_{2} \mathrm{CO}, \mathrm{D}_{2} \mathrm{O}$

Directed lithiation of $\mathrm{N}$-(2-methoxybenzyl)pivalamide with two mole equivalents of $t$-BuLi in anhydrous THF at $-78^{\circ} \mathrm{C}$ followed by reactions with various electrophiles gave ring substitution, but ortho- to the methoxy group rather than ortho- to the pivaloylaminomethyl group, which was unexpected in view of earlier results reported with sec-BuLi.

Regioselective synthesis of substituted aromatics is one of the classical problems in synthetic chemistry. Simple electrophilic substitution often leads to various isomers and polysubstituted aromatics and usually takes place under forcing conditions in the presence of a catalyst. In recent years, many efforts have been made to develop clean and environmentally friendly processes for the regioselective production of specific products and it is well recognized that organolithium reagents ${ }^{1-2}$ can play an important role in such cases. In particular, lithiation of aromatic compounds often occurs proximal to substituents that possess oxygen or nitrogen atoms. ${ }^{3}$ As a result, lithiation of aromatics or heterocycles followed by treatment with an electrophile is one of the most efficient approaches for synthesis of substituted and/or modified derivatives. ${ }^{4,5}$

Simig and Schlosser have reported that lithiation of $N$-(4-methoxybenzyl)pivalamide using sec-BuLi at $0{ }^{\circ} \mathrm{C}$, followed by treatment with carbon dioxide, results in carboxylation at the 2-position, ortho- to the pivaloylaminomethyl group, rather than ortho- to the methoxy group. The product was isolated in $64 \%$ yield. ${ }^{6}$ By contrast, treatment of $N$-(2-methoxybenzyl)pivalamide in the same way gave a mixture of two products, one of which involved carboxylation ortho- to the pivaloylaminomethyl group (isolated in 10\% yield by 
fractional crystallization), and the other of which involved carboxylation at the side-chain (isolated in 14\% yield as the ester following treatment of the residue with diazomethane). ${ }^{6}$ The poor regioselectivity and low yields achieved in the latter reaction render the process unattractive as a synthetic method. However, it was not clear whether the lithiation reaction would proceed in the same way under different reaction conditions (e.g. different lithium reagents, reaction temperatures or times) or using electrophiles other than carbon dioxide.

Based on our own experience in the use of lithium reagents in organic synthesis and in directed lithiation reactions, ${ }^{7}$ we felt that it ought to be possible to develop a general, simple and efficient regioselective lithiation procedure for $N$-(2-methoxybenzyl)pivalamide, to enable convenient syntheses of the corresponding substituted derivatives. Therefore, we decided to undertake a wider investigation of the directed lithiation of this compound. The results, which we now report, show unexpected variations in the site of lithiation. As a result, we have been able to establish conditions for a high-yielding and general ring-substitution, but at the position ortho- to the methoxy group rather than ortho- to the pivaloylaminomethyl group. Lithiation at this site was not observed at all under the conditions used by Simig and Schlosser. ${ }^{6}$

The first task was to carry out lithiation of $N$-(2-methoxybenzyl)pivalamide (1) under Schlosser's conditions, using sec-BuLi as the lithium reagent at $0{ }^{\circ} \mathrm{C}$, followed by reaction with carbon dioxide. Therefore, compound 1 was treated with sec-BuLi (2.2 mole equivalents) at $0{ }^{\circ} \mathrm{C}$ in anhydrous THF under nitrogen and the reddish brown solution obtained was stirred for $2 \mathrm{~h}$ at $0{ }^{\circ} \mathrm{C}$. Solid carbon dioxide was added and the reaction mixture was stirred for 30 minutes. The mixture was diluted with ethyl acetate and quenched with dilute $\mathrm{HCl}$. The crude product obtained was crystallized from ethyl acetate to give white crystals of 3-methoxy-2(pivaloylaminomethyl)benzoic acid, 2, obtained in $25 \%$ yield (Scheme 1). The structure of 2 was confirmed by x-ray crystallography (Figure 1).

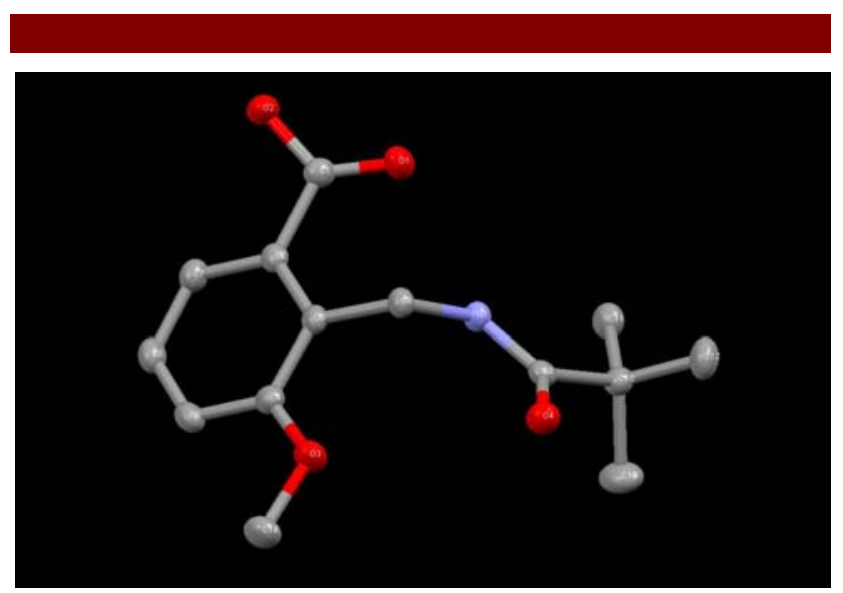

Figure 1. X-ray crystal structure of compound 2
The ${ }^{1} \mathrm{H}$ NMR spectrum of the mother liquor after crystallization showed the presence of additional 2 and another major product, readily identified as $\mathbf{3}$ (Scheme 1), in the ratio of $1: 2$, along with traces of $\mathbf{1}$. No attempt was made to isolate 3 , but the mother liquor accounted for $c a$. $70 \%$ of the initial substrate, indicating that the total yield of the two carboxylic acids was in the range of $94 \%$ and that $\mathbf{2}$ and 3 were each produced in about $46 \%$ yield each. These results are consistent with Schlosser's findings and imply that difficulty in isolation of the products from the reaction mixture was the reason for the low yields reported rather than that lithiation was ineffective.

Our initial variation of the procedure involved lithiation of compound 1 with $t$ - BuLi (2.2 mole equiv.) at $0{ }^{\circ} \mathrm{C}$ followed by reaction with carbon dioxide, under conditions close to those used by Schlosser except for the nature of the alkyllithium. The ${ }^{1} \mathrm{H}$ NMR spectrum of the crude product showed the presence of three products, identified as 2, 3 and 2-methoxy-3(pivaloylaminomethyl)benzoic acid (4), in the ratio of 1:4:5. Two of the acids, 2 and $\mathbf{4}$, were separated in pure forms, in yields of $5 \%$ and $40 \%$, respectively, by fractional crystallization of the crude product using ethyl acetate. The structure of compound $\mathbf{4}$ was confirmed by $\mathrm{x}$-ray crystallography (Figure 2).

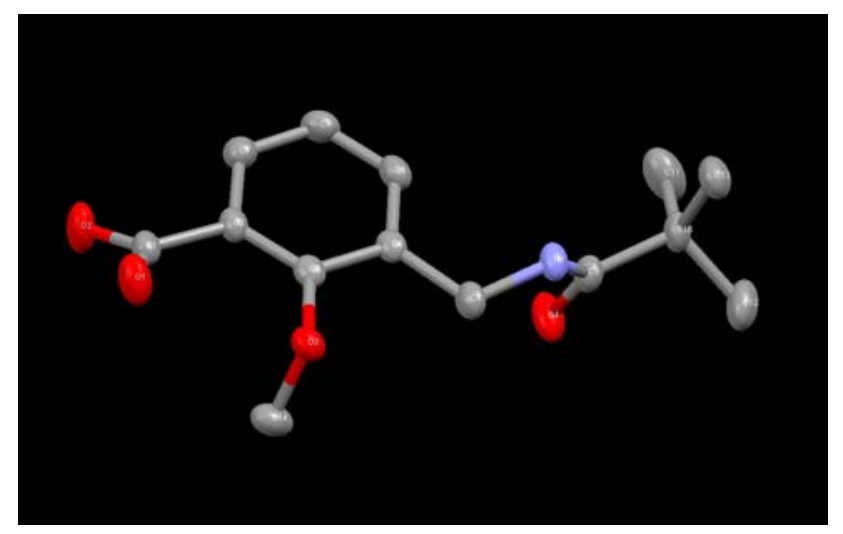

Figure 2. X-ray crystal structure of 4

The ring-substituted product 2 was the one expected based on Simig and Schlosser's work with sec-BuLi, ${ }^{6}$ but it was obtained in only low yield as a minor product using $t$-BuLi at $0{ }^{\circ} \mathrm{C}$. Compound 4 was obtained as the major acid, presumably resulting from lithiation at the position ortho- to the methoxy group rather than ortho- to the pivaloylaminomethyl group. This unexpected result clearly indicated that the selectivity of reaction of $\mathbf{1}$ with lithium reagents, followed by reaction with carbon dioxide, is strongly dependent on the type of lithium reagent used. We next investigated the effect of lowering the temperature of lithiation to- $78^{\circ} \mathrm{C}$. 
Scheme 1. Lithiation of 1 followed by reaction with $\mathrm{CO}_{2}$ under Schlosser's conditions ${ }^{6}$

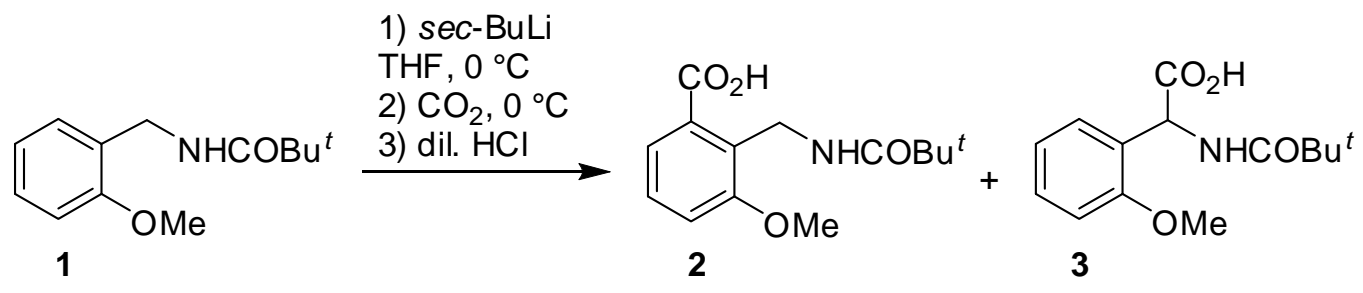

Compound 1 was treated with sec-BuLi at $-78^{\circ} \mathrm{C}$ and the reddish brown solution obtained was stirred for $4 \mathrm{~h}$ at $-78{ }^{\circ} \mathrm{C}$. The cooling bath was removed and solid carbon dioxide was added. The reaction mixture was stirred for 30 minutes while the temperature slowly rose. The mixture was diluted with ethyl acetate and quenched with dilute $\mathrm{HCl}$. The ${ }^{1} \mathrm{H}$ NMR spectrum of the crude product showed the presence of $\mathbf{1}, \mathbf{2}$ and $\mathbf{3}$ in the ratio of $c a$. $2: 2: 3$. There was no evidence for the formation of 4 under the conditions tried. The results showed that the reaction had not gone to completion under the conditions used but that it was somewhat more selective for side-chain substitution than at $0{ }^{\circ} \mathrm{C}$. However, it was still not a useful synthetic procedure.

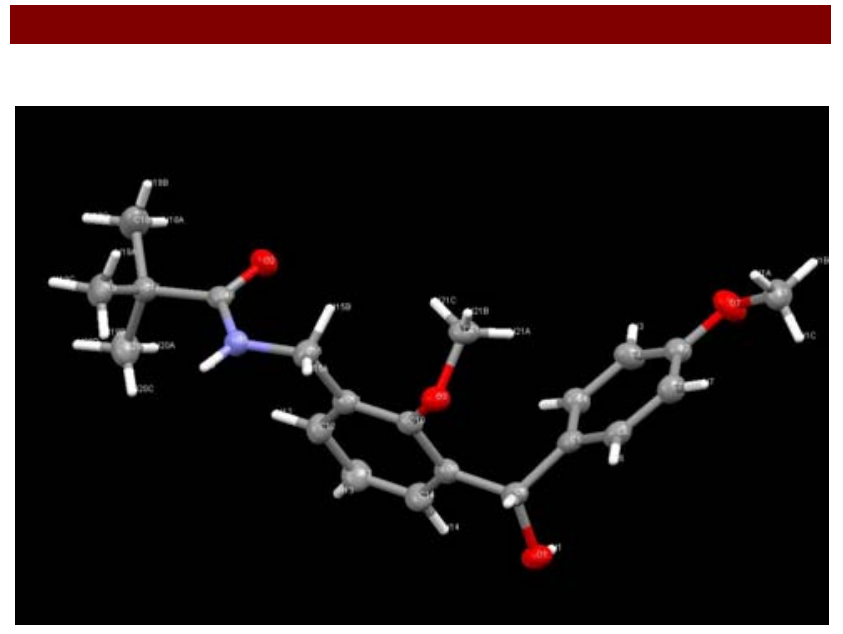

Figure 3. X-ray crystal structure of compound 5

A similar reaction was carried out with $t$-BuLi rather than sec-BuLi. In this case it was possible to isolate pure 4 in $80 \%$ yield following crystallisation of the crude product. The mother liquor showed the presence of $\mathbf{3}$ and additional $\mathbf{4}$ in nearly equal proportions along with traces of $\mathbf{1}$, suggesting that $\mathbf{3}$ and $\mathbf{4}$ were produced in approximately $9 \%$ and $89 \%$ yields, respectively. Clearly, $t-\mathrm{BuLi}$ is both more effective and more regioselective than sec-BuLi under these conditions and again causes lithiation at a different ring position. The reaction appeared to have potential as a synthetic method and therefore the same lithiation procedure was used for reactions with a range of different electrophiles. Following work-up of the reaction mixture the crude products were purified by column chromatography (silica gel; $\mathrm{Et}_{2} \mathrm{O}$-hexane, 1:3) or direct crystallization from ethyl acetate to give the corresponding $N$-(3-substituted 2-methoxybenzyl)pivalamides 4-8 in high yields (Table 1).

Table 1. Synthesis of $N$-(3-Substituted 2-methoxybenzyl)pivalamides 4-8 via Lithiation and Substitution of 1

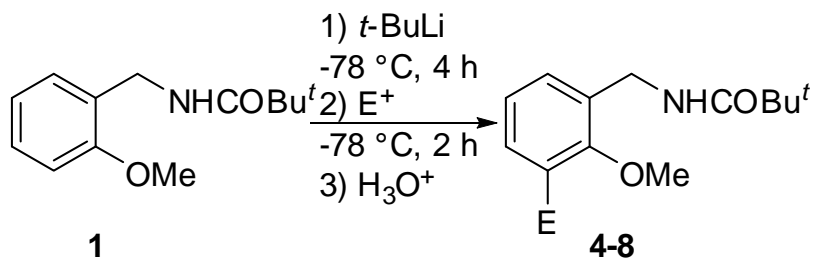

1

4-8

Electrophile $\left(\mathrm{E}^{+}\right)=\mathrm{CO}_{2}, 4-\mathrm{MeOC}_{6} \mathrm{H}_{4} \mathrm{CHO}$ $\mathrm{PhCHO}, \mathrm{Ph}_{2} \mathrm{CO}, \mathrm{D}_{2} \mathrm{O}$

\begin{tabular}{|c|c|c|c|}
\hline Product & Electrophile & $\mathrm{E}$ & Yield $(\%)^{a}$ \\
\hline $4^{b}$ & $\mathrm{CO}_{2}$ & $\mathrm{CO}_{2} \mathrm{H}$ & 80 \\
\hline $5^{c, d}$ & $4-\mathrm{MeOC}_{6} \mathrm{H}_{4} \mathrm{CHO}$ & $4-\mathrm{MeOC}_{6} \mathrm{H}_{4} \mathrm{CH}(\mathrm{OH})$ & $76^{e}$ \\
\hline $6^{c}$ & $\mathrm{PhCHO}$ & $\mathrm{PhCH}(\mathrm{OH})$ & 75 \\
\hline 7 & $\mathrm{Ph}_{2} \mathrm{CO}$ & $\mathrm{Ph}_{2} \mathrm{C}(\mathrm{OH})$ & $73^{f}$ \\
\hline 8 & $\mathrm{D}_{2} \mathrm{O}$ & $\mathrm{D}$ & 86 \\
\hline \multicolumn{4}{|c|}{$\begin{array}{l}\quad \text { Yield of isolated product after purification by column } \\
\text { chromatography unless otherwise indicated. }{ }^{b} \text { Compound } 4 \text { was purified } \\
\text { by crystallization from ethyl acetate. }{ }^{c} \text { The structure of compound } 5 \text { was } \\
\text { confirmed by x-ray crystallography (Figure } 3 \text { ). }{ }^{d} \text { The }{ }^{1} \mathrm{H} \text { NMR spectra of } \\
5 \text { and } \mathbf{6} \text { showed the } \mathrm{CH}_{2} \text { hydrogens as two separated double doublets, } \\
\text { verifying that they are diastereotopic. }{ }^{e} \text { Compound } \mathbf{9} \text { (Figure } 4 \text { ) was } \\
\text { obtained as a side product in } 3 \% \text { yield. }{ }^{f} \text { Compound } \mathbf{1 0} \text { (Figure } 4 \text { ) was } \\
\text { obtained as a side product in } 3 \% \text { yield. }\end{array}$} \\
\hline
\end{tabular}

Clearly, this procedure represents a simple, efficient and high yielding route for substitution of $\mathrm{N}$-(2methoxybenzyl)pivalamide. It is not clear why lithiation of $N$-(2-methoxybenzyl)pivalamide with $t$-BuLi in THF at $-78{ }^{\circ} \mathrm{C}$ gives substitution ortho- to the methoxy group while a similar procedure with sec-BuLi gives a mixture containing two different substitution products, one of 
which involves lithiation ortho- to the pivaloylaminomethyl group. It could have something to do with the way the reagents aggregate, their ability to chelate the two substituents or the relative bulk of the alkyl groups, but without further information it is not easy to decide.<smiles>COc1ccc(C(O)C(NC(=O)OC(C)(C)C)c2ccccc2OC)cc1</smiles>

Figure 4. Structures of compounds $\mathbf{9}$ and $\mathbf{1 0}$

In summary, $N$-(2-methoxybenzyl)pivalamide (1) undergoes lithiation with $t$-BuLi at $-78{ }^{\circ} \mathrm{C}$, followed by treatment with electrophiles, to give high yields of the corresponding substituted products 4-8 having the substituent ortho- to the methoxy group. In contrast, use of sec-BuLi under similar conditions gives almost none of this product, leading instead to mixtures of two products, one substituted on the side-chain (pivaloylaminomethyl group) and the other on the ring ortho- to the pivaloylaminomethyl group.

Acknowledgment. We thank Dr Benson Kariuki, xray crystallography service at Cardiff School of Chemistry, and the EPSRC National Crystallography Service for the crystal structures. A. S. Hegazy thanks Cardiff University for financial support.

Supporting Information Available: Experimental procedures and spectroscopic data for all compounds and tables of crystallographic data for 2, 4 and 5 .

(1) (a) Clayden, J. Organolithiums: Selectivity for Synthesis, Tetrahedron Organic Chemistry Series, Vol. 23, Pergamon: Oxford, 2002. (b) Schlosser, M. Organometallics in Synthesis, 2nd ed.; Wiley: Chichester, 2002; pp. 1-352.

(2) See for example: (a) Gschwend, H. W.; Hamdan, A. J. Org. Chem. 1975, 40, 2008-2009. (b) Fitt, J. J.; Gschwend, H. W. J. Org. Chem. 1976, 41, 4029-4031. (c) Fuhrer, W.; Gschwend, H. W. J. Org. Chem. 1979, 44, 1133-1136. (d) Peter, P.; Snieckus, V. Acc. Chem. Res., 1982, 15, 306-312. (e) Nájera, C.; Sansano, J. M.; Yus, M. Tetrahedron 2003, 59, 9255-9303 (f) Schlosser, M. Angew. Chem. Int. Ed. 2005, 44, 376-399. (g) Chadwick, S. T.; Ramirez, A.; Gupta, L.; Collum, D. B. J. Am. Chem. Soc. 2007, 129, 2259-2268.

(3) See for example: (a) Beak, P.; Zajdel, W. J.; Reitz, D. B. Chem. Rev. 1984, 84, 471-523. (b) Snieckus, V. Chem. Rev. 1990, 90, 879933. (c) El-Hiti, G. A. Heterocycles 2000, 53, 1839-1868. (d) Mongin, F.; Quéguiner, G. Tetrahedron 2001, 57, 4059-4090. (e) Turck, A.; Plé, N.; Mongin, F.; Quéguiner, G. Tetrahedron 2001, 57, 4489-4505. (f) Anctil, E. J.-G.; Snieckus, V. J. Organomet. Chem. 2002, 653, 150-160. (g) Smith, K.; El-Hiti, G. A. Curr. Org. Synth. 2004, 1, 253-274. (h) Chinchilla, R.; Nájera, C.; Yus, M. Chem. Rev. 2004, 104, 2667-2722. (i) Foubelo, F.; Yus, M. Curr. Org. Chem. 2005, 9, 459-490. (j) Rathman, T. L.; Bailey, W. F. Org. Process Res. Dev. 2009, in press.
(4) Recent examples for substituted benzenes: (a) Clayden, J.; Turner, H.; Pickworth, M.; Adler, T. Org. Lett. 2005, 7, 3147-3150. (b) Chodakowski, J.; Kliś, T.; Serwatowski, J. Tetrahedron Lett. 2005, 46, 1963-1965. (c) Clayden, J.; Dufour, J. Tetrahedron Lett. 2006, 47 6945-6949. (d) Burgos, P. O.; Fernández, I.; Iglesias, M. J.; GarcíaGranda, S.; Ortiz, F. L. Org. Lett. 2008, 10, 537-540. (e) Wilkinson, J. A.; Raiber, E.-A.; Ducki, S. Tetrahedron 2008, 64, 6329-6333. (f) Porcs-Makkay, M.; Komáromi, A.; Lukács, G.; Simig, G. Tetrahedron 2008, 64, 1029-1033. (g) Castanet, A.-S.; Tilly, D.; Véron, J.-B.; Samanta, S. S.; De, A.; Ganguly, T.; Mortier, J. Tetrahedron 2008, 64, 3331-3336. (h) Michon, C.; Murai, M.; Nakatsu, M.; Uenishi, J.; Uemura M. Tetrahedron, 2009, 65, 752-756.

(5) Recent examples for substituted heterocycles: (a) Philipova, I.; Dobrikov, G.; Krumova, K.; Kaneti, J. J. Heterocycl. Chem. 2006, 43, 1057-1063. (b) Robert, N.; Bonneau, A.-L.; Hoarau, C.; Marsais, F. Org. Lett. 2006, 8, 6071-6074. (c) Aliyenne, A. O.; Khiari, J. E.; Kraïem, J.; Kacem, Y.; Hassine, B. B. Tetrahedron Lett. 2006, 47, 6405-6408. (d) Comoy, C.; Banaszak, E.; Fort, Y. Tetrahedron 2006, 62, 6036-6041. (e) Luisi, R.; Capriati, V.; Florio, S.; Musio, B. Org. Lett. 2007, 9, 1263-1266. (f) Clayden, J.; Hennecke, U. Org. Lett. 2008, 10, 3567-3570. (g) McLaughlin, M.; Marcantonio, K.; Chen, C.; Davies, I. W. J. Org. Chem. 2008, 73, 4309-4312. (h) Capriati, V.; Florio, S.; Luisi, R.; Mazzanti, A.; Musio, B. J. Org. Chem. 2008, 73 , 3197-3204. (i) Affortunato, F.; Florio, S.; Luisi, R.; Musio B.J. Org. Chem. 2008, 73, 9214-9220.

(6) Simig, G.; Schlosser, M. Tetrahedron Lett. 1988, 29, 4277-4280.

(7) See for example: (a) Smith, K.; El-Hiti, G. A.; Abdo, M. A.; Abdel-Megeed M. F. J. Chem. Soc., Perkin Trans. 1 1995, 1029-1033. (b) Smith, K.; El-Hiti, G. A.; Abdel-Megeed, M. F.; Abdo, M. A. J. Org. Chem. 1996, 61, 647-655. (c) Smith, K.; El-Hiti, G. A.; Abdel-Megeed, M. F.; Abdo, M. A. J. Org. Chem. 1996, 61, 656-661. (d) Smith, K.; ElHiti, G. A.; Pritchard, G. J.; Hamilton, A. J. Chem. Soc., Perkin Trans. 1 1999, 2299-2303. (e) Smith, K.; El-Hiti, G. A.; Shukla, A. P. J. Chem. Soc., Perkin Trans. 1 1999, 2305-2313. (f) Smith, K.; El-Hiti, G. A.; Hawes, A. C. Synthesis 2003, 2047-2052. (g) Smith, K.; El-Hiti, G. A.; Mahgoub, S. A. Synthesis 2003, 2345-2348. (h) El-Hiti, G. A. Synthesis 2003, 2799-2804 (i) Smith, K.; El-Hiti, G. A.; Abdel-Megeed, M. F. Synthesis 2004, 2121-2130. (j) El-Hiti, G. A. Synthesis 2004, 363-368. (k) Smith, K.; El-Hiti, G. A.; Hegazy, A. S. Synthesis 2005, 2951-2961. (l) Smith, K.; Barratt, M. L. J. Org. Chem. 2007, 72, 1031-1034. 